\title{
Role of telavancin in treatment of skin and skin structure infections
}

Joseph Bonkowski'

Anne R Daniels ${ }^{2}$

William J Peppard ${ }^{2}$

'University of Wisconsin-Madison, Madison, WI, USA; ${ }^{2}$ Froedtert

Hospital, Milwaukee, WI, USA
Correspondence: Anne R Daniels Froedtert Hospital Pharmacy, 9200 West Wisconsin Avenue, Milwaukee, WI 53226, USA

$\mathrm{Tel}+\mathrm{I} 4 \mid 48056446$

Fax +l 4|48056702

Email arygiewi@froedterthealth.org
This article was published in the following Dove Press journal:

Clinical, Cosmetic and Investigational Dermatology

6 October 2010

Number of times this article has been viewed
Abstract: Skin and skin structure infections (SSSIs) are a common diagnosis encountered by ambulatory and inpatient practitioners across the country. As the SSSIs become more complicated, they require increased health care resources and often involve hospitalization and intravenous antimicrobials. Complicated SSSIs are caused by a variety of pathogens, including Gram-positive, Gram-negative, and anerobic bacteria. Empiric broad-spectrum antibiotic coverage is warranted, taking into account area disease-state epidemiology and antimicrobial susceptibility data. Telavancin is an antimicrobial agent with a broad Gram-positive spectrum of activity which was recently approved for the treatment of SSSIs. It may especially benefit patients with resistant organisms, such as methicillin-resistant Staphylococcus aureus. This article reviews telavancin and its pharmacology, efficacy, and safety data to enhance the practitioner's knowledge base on the appropriateness of telavancin for the treatment of SSSIs.

Keywords: skin and skin structure infections, telavancin, methicillin-resistant Staphylococcus aureus

\section{Introduction}

Skin and skin structure infections (SSSIs) are a frequent indication for hospitalization and antibiotic treatment in the US. ${ }^{1}$ More specifically, they can be further delineated as uncomplicated or complicated SSSIs, based on the degree of tissue involvement. ${ }^{2}$ Uncomplicated SSSIs include superficial cellulitis, folliculitis, furunculosis, simple abscesses, and minor wound infections. Uncomplicated SSSIs involving the epidermis and dermis usually respond to a course of enteral antibiotics with or without incision and drainage. Complicated SSSIs involve invasion of deeper structures such as subcutaneous tissue, fascia, or muscle. They potentially require significant surgical interventions, especially in patients demonstrating a poor response to initial antibiotic therapy secondary to underlying disease states, such as diabetes mellitus, vascular insufficiency, sensory neuropathies, obesity, poor hygiene, or certain immunodeficiencies. Complicated SSSIs include complicated skin abscesses, infected burns and ulcers, and deep space wound infections. ${ }^{3}$

Various bacteria may be involved in SSSIs, depending upon the disease process, clinical presentation, and environment. Beta-hemolytic streptococci and Staphylococcus aureus are the most common isolated pathogens. However, $\beta$-hemolytic streptococci are likely underrepresented as a pathogen because superficial cellulitis does not require hospitalization, and adequate cultures are difficult and unnecessary to attain in less complicated infections. The most common pathogen, $S$. aureus, is recognized in $44 \%$ of SSSIs in North America (Figure 1). ${ }^{4}$ However, as the SSSI becomes more 
complicated, the incidences of Gram-negative and anerobic microorganisms increase.

Over the last 20 years, there has been a dramatic increase in methicillin-resistant $S$. aureus (MRSA) in patients with no known contact with health care institutions or other risk factors for acquiring hospital-associated MRSA; these strains are referred to as community-associated MRSA. ${ }^{5}$ Community-associated MRSA, a genetically unique organism which carries the gene that encodes Panton-Valentine leukocidin, a deadly exotoxin, is commonly associated with SSSI acquired in the outpatient setting. ${ }^{6}$ This exotoxin is the key characteristic associated with community-associated MRSA, which causes necrosis of the skin and abscess formation. ${ }^{7,8}$ This directly impacts empiric antimicrobial choices in the outpatient setting because community-associated MRSA is not susceptible to cephalosporins (excluding ceftobiprole and ceftaroline) and anti-staphylococcal penicillins. However, community-associated MRSA does maintain susceptibility to enteral antimicrobials including tetracyclines, trimethoprim-sulfamethoxazole, clindamycin, and linezolid. ${ }^{3}$ Patients with complicated SSSI requiring hospitalization are routinely started on intravenous broadspectrum antimicrobial agents which maintain activity against both community-associated MRSA and hospital-associated MRSA, such as vancomycin, linezolid, daptomycin, tigecycline, and quinupristin/dalfopristin (Pfizer, Cubist, Wyeth, King). These intravenous antimicrobial agents should then be de-escalated to appropriate enteral therapy based on culture and sensitivity results. As of September 2009, another intravenous antimicrobial agent with activity against MRSA has become available, ie, telavancin. ${ }^{9}$ Identification of medical literature on the role of telavancin in the treatment of SSSI was done through an Ovid Medline ${ }^{\circledR}$ literature search.

\section{Pharmacology}

Telavancin is a lipoglycopeptide antibiotic with a dual mechanism of action. Like other glycopeptides, telavancin inhibits bacterial cell wall synthesis by binding to the terminal D-Ala-D-Ala of newly formed peptidoglycan chains. This prevents crosslinking and polymerization of the cell wall. Despite having a fivefold reduced affinity for the D-Ala-D-Ala moiety, telavancin is 10 times more potent than vancomycin in the inhibition of peptidoglycan synthesis. Telavancin also increases bacterial cell membrane permeability which leads to efflux of intracellular adenosine5 -triphosphate and potassium. This quickly decreases the cell membrane potential and gives telavancin its rapid concentration-dependent bactericidal activity. ${ }^{10}$

Telavancin contains the same structural core as vancomycin, with two significant differences. First, a lipophilic side chain on the vancosamine sugar extends the serum half-life and increases antimicrobial activity against resistant $S$. aureus and Enterococcus species. Second,
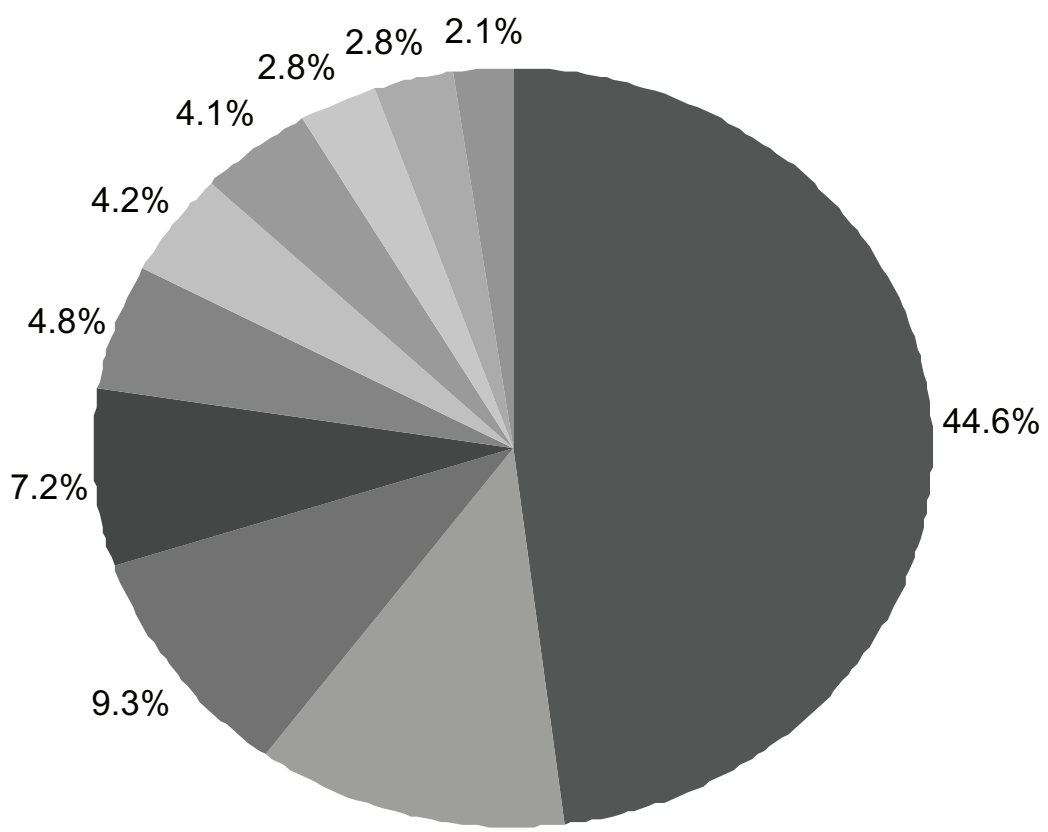

Staphylococcus aureus $44.6 \%$

Pseudomonas aeruginosa $11.1 \%$

Enterococcus spp 9.3\%

Escherichia coli 7.2\%

Enterobacter spp $4.8 \%$

Klebsiella spp $4.2 \%$

B-Streptococcus $4.1 \%$

Proteus mirabilis $2.8 \%$

Coagulase-negative

Staphylococcus $2.8 \%$

Serratia spp $2.1 \%$

$11.1 \%$

Figure I Most common bacterial pathogens producing skin and soft tissue infections in North America (1998-2004).

Copyright (C) 2007. Adapted with permission from Moet G], Jones RN, Biedenbach DJ, Stilwel MG, Fritsche TR. Contemporary causes of skin and soft tissue infection in North America, Latin America, and Europe: report from SENTRY Antimicrobial Surveillance Program (1998-2004). Diagn Microbiol Infect Dis. 2007;57:7-13. 
a polar phophonomethyl aminomethyl group enhances tissue penetration, but reduces the serum half-life of the compound by promoting renal clearance. ${ }^{11}$ The net result is a prolonged half-life as compared with vancomycin.

\section{Pharmacokinetics}

Telavancin is only available as an intravenous formulation, because glycopeptides have poor systemic absorption following enteral administration. When telavancin infuses over 30-120 minutes as single doses of $1-12.5 \mathrm{mg} / \mathrm{kg}$ or multiple once-daily doses of $7.5-15 \mathrm{mg} / \mathrm{kg}$, it exhibits linear pharmacokinetics and achieves steady state by the third daily dose, as demonstrated in a two-part, randomized, double-blind, placebo-controlled, dose-escalation study in 54 healthy male volunteers over a period of seven days. ${ }^{12}$ Another study assessed the pharmacokinetic parameters utilizing a randomized, double-blind, parallel-group, genderstratified, two-dose method in 79 adult subjects over a period of three days. Dose-proportional increases in mean peak serum concentrations and total systemic exposure were observed, similar to the results from the first study. ${ }^{13}$ A third study observed healthy young adults receiving single $(n=42)$ or multiple doses $(n=36)$ of telavancin $10 \mathrm{mg} / \mathrm{kg}$ infused over 60 minutes. The mean peak serum concentrations were 93.6 and $108 \mu \mathrm{g} / \mathrm{mL}$ and the area under the serum concentration curves were $666 \mu \mathrm{g} \cdot \mathrm{hr} / \mathrm{mL}$ and $780 \mu \mathrm{g} \cdot \mathrm{hr} / \mathrm{mL}$, respectively. ${ }^{9}$ It exhibits a steady-state volume of distribution of about $0.1 \mathrm{~L} / \mathrm{kg}$ and is $90 \%-93 \%$ bound by plasma proteins. The terminal half-life of telavancin is about 7-9 hours, and it displays a postantibiotic effect of 4-6 hours. These characteristics allow for oncedaily dosing of telavancin. Renal clearance of telavancin accounts for $65 \%-72 \%$ of plasma clearance, and two-thirds of the total dose is excreted in the urine unchanged. ${ }^{13}$ The metabolism of telavancin has not been fully described, but it does not have a clinically relevant effect on the cytochrome p450 enzyme systems. ${ }^{14}$

In patients with normal hepatic and renal function, the recommended dose of telavancin is $10 \mathrm{mg} / \mathrm{kg}$ intravenously every 24 hours. There are no gender- or age-related differences in the plasma pharmacokinetics of telavancin. ${ }^{13}$ Telavancin has not been studied in pediatric patients. Dose adjustment of telavancin is recommended for renal impairment because of increased drug accumulation with worsening creatinine clearance and the potential for increased accumulation of hydroxypropyl-beta-cyclodextrin, a solubilizing agent present in the intravenous formulation. ${ }^{9}$ In patients with creatinine clearance of $30-50 \mathrm{~mL} / \mathrm{min}$,
$75 \%$ of the total dose should be administered at the same dosing interval. For those with creatinine clearance of $10-29 \mathrm{~mL} / \mathrm{min}$, the full dose should be given every 48 hours. ${ }^{11}$ There are no specific dosing recommendations for telavancin in patients with end-stage renal disease, on hemodialysis, or on continuous renal replacement therapy, because of limited patient populations. However, in Phase III studies, patients on hemodialysis received telavancin $10 \mathrm{mg} / \mathrm{kg}$ every 48 hours. No supplemental dose was administered after dialysis, given that telavancin is poorly cleared by dialysis. Continuous hemodialysis and continuous hemofiltration have been shown to significantly clear telavancin in an in vitro model. ${ }^{15}$

\section{Spectrum of activity}

Telavancin demonstrates broad in vitro activity against a number of Gram-positive organisms, including those resistant to other antimicrobial agents such as MRSA (Table 1). When assessing the minimum inhibitory concentrations necessary to inhibit $90 \%\left(\mathrm{MIC}_{90}\right)$ of the target bacterial strains, telavancin demonstrates excellent activity against $S$. aureus (including MRSA isolates). For both methicillin-susceptible $S$. aureus and MRSA, $\mathrm{MIC}_{90}$ breakpoints were in the range $0.25-1 \mathrm{mg} / \mathrm{L}$. However, the telavancin $\mathrm{MIC}_{90}$ was slightly elevated in glycopeptide-intermediate staphylococcal species. At $1 \mathrm{mg} / \mathrm{L}$, telavancin also possesses excellent streptococci coverage, including multidrug-resistant strains. Multidrug-resistant and penicillin-susceptible Streptococcus pneumoniae both have $\mathrm{MIC}_{90}$ values of $0.03 \mathrm{mg} / \mathrm{L}$. Beta-hemolytic streptococci and viridans streptococci have low $\mathrm{MIC}_{90}$ values in the ranges $0.001-0.25 \mathrm{mg} / \mathrm{L}$ and $0.001-1 \mathrm{mg} / \mathrm{L}$, respectively. Vancomycin-susceptible Enterococcus faecalis and Enterococcus faecium are also susceptible to telavancin, with $\mathrm{MIC}_{90}$ breakpoints of $\leq 1 \mathrm{mg} / \mathrm{L}$. However, when the Enterococcus strains are resistant to vancomycin, the $\mathrm{MIC}_{90}$ values are elevated, with $E$. faecalis in the range $4-16 \mathrm{mg} / \mathrm{L}$ and $E$. faecium in the range $2-8 \mathrm{mg} / \mathrm{L}$. Telavancin is also effective against anerobic Gram-positive organisms and Cornyebacterium species. Telavancin demonstrates no activity against Gram-negative organisms. ${ }^{16}$

\section{Efficacy of telavancin in clinical trials}

Two Phase II and two Phase III clinical trials were submitted to the US Food and Drug Administration (FDA) for approval of telavancin. The first Phase II trial, conducted by the FAST study group, evaluated the efficacy of telavancin for complicated 
Table I Activity of telavancin and other comparators for Gram-positive clinical isolates

\begin{tabular}{|c|c|c|c|c|c|}
\hline \multirow[t]{2}{*}{ Organism } & \multicolumn{5}{|c|}{ Agent and $\mathrm{MIC}_{90}(\mu \mathrm{g} / \mathrm{mL})$} \\
\hline & Telavancin & Vancomycin & Linezolid & Daptomycin & $\begin{array}{l}\text { Quinipristin- } \\
\text { dalfopristin }\end{array}$ \\
\hline MSSA & 0.5 & 1 & 2 & 0.5 & 0.5 \\
\hline MRSA & 0.25 & 1 & 2 & 0.5 & 0.5 \\
\hline $\begin{array}{l}\text { E. faecalis vancomycin- } \\
\text { susceptible }\end{array}$ & 1 & 2 & 0.25 & 1 & 1 \\
\hline $\begin{array}{l}\text { E. faecalis harboring } \\
\text { van A }\end{array}$ & 16 & $>512$ & 2 & 1 & $\mathrm{n} / \mathrm{a}$ \\
\hline $\begin{array}{l}\text { E. faecium vancomycin } \\
\text { susceptible }\end{array}$ & 0.25 & 1 & 2 & 4 & 2 \\
\hline $\begin{array}{l}\text { E. faecium harboring } \\
\text { van } \mathrm{A}\end{array}$ & 8 & 512 & 2 & 4 & 1 \\
\hline $\begin{array}{l}\text { E. faecium harboring } \\
\operatorname{van} B\end{array}$ & 2 & 0.5 & 1 & 4 & 4 \\
\hline
\end{tabular}

Abbreviations: MSSA, methicillin-susceptible Staphylococcus aureus; MRSA, methicillin-resistant Staphylococcus aureus; MIC $_{90}$, minimum inhibitory concentration. Copyright $(\underset{ }{ }$ 2008. Adapted with permission from Draghi DC, Benton BM, Krause KM, Thornsberry C, Pillar C, Sahm DF. Comparative surveillance study of telavancin activity against recently collected gram-positive clinical isolates from across the United States. Antimicrob Agents Chemother. 2008;52:2383-2388.

SSSIs caused by Gram-positive bacteria. ${ }^{17}$ In this double-blind, parallel-group, multinational clinical trial, 167 patients with suspected or confirmed Gram-positive complicated SSSI, were randomized in a $1: 1$ ratio to receive $7.5 \mathrm{mg} / \mathrm{kg}$ telavancin intravenously once a day or standard therapy. Standard therapy was defined as intravenous vancomycin 1 g every 12 hours, nafcillin or oxacillin $2 \mathrm{~g}$ every six hours, or cloxacillin $0.5-1 \mathrm{~g}$ every six hours. Vancomycin monitoring and dosing varied according to the standards at each institution. Therapy was continued for 4-14 days depending on location and severity of infection. The primary endpoint was to assess clinical response in the clinically evaluable population, with cure defined as the resolution of clinically significant signs and symptoms of complicated SSSI and if there was eradication of a pathogen in the microbiologically evaluable patients at the test of cure evaluation occurring 7-14 days after the last dose was administered. Patient characteristics were similar between the treatment groups at baseline, and pathogens were isolated in $81 \%$ of the total treated population. Of the pathogens isolated, $53 \%$ were $S$. aureus (of which $49 \%$ were methicillin-resistant), $22 \%$ were Gram-negative bacteria, and 12\% were nonenterococcal streptococci. In the total randomized population, the primary endpoint was achieved in $79 \%$ of patients in the telavancin group and $80 \%$ of patients in the standard therapy group $(P=0.53)$. In patients with $S$. aureus infection, cure was attained in $80 \%$ of those in the telavancin group and $77 \%$ in the standard therapy group $(P=0.80)$. In MRSA infections, the telavancin and standard therapy groups had $82 \%$ and $69 \%$ cure rates, respectively $(P=1.00)$. The differences in cure rates between treatment groups were not clinically or statistically significant. Treatment with telavancin was associated with four serious adverse events, compared with nine events in the standard therapy group. Discontinuation of therapy due to adverse events occurred at a rate of 5\% in both treatment groups.

Another Phase II trial was conducted by the FAST 2 study group. ${ }^{18}$ This double-blind, parallel-group, multinational clinical trial randomized 195 patients to either telavancin $10 \mathrm{mg} / \mathrm{kg}$ intravenously once a day or standard therapy. Standard therapy and therapy length was defined the same as for the previous FAST trial. Baseline patient characteristics were similar between treatment groups. At least one pathogen was identified in $82 \%$ of the study population. Of the pathogens isolated, 52\% were $S$. aureus, $19 \%$ were Gram-negative bacteria, and 16\% were nonenterococcal streptococci. In the total randomized population, cure was achieved by $82 \%$ of patients in the telavancin group and $85 \%$ of patients in the standard therapy group $(P=0.37)$. Among patients with $S$. aureus isolates, cure was achieved by $96 \%$ in the telavancin group and $90 \%$ in the standard therapy group $(P=0.36)$. Cure rates for both treatment groups in patients with MRSA was the same as those observed for $S$. aureus. These results were not statistically significant between treatment groups. Treatment with telavancin was associated with a $6 \%$ rate of serious adverse events, compared with a $4 \%$ rate in the standard therapy group. Adverse events led to discontinuation of therapy in $6 \%$ of patients treated with telavancin and 3\% in the standard therapy group.

The only Phase III trials evaluating telavancin for complicated SSSI, with abscess and cellulitis being the most common baseline diagnoses, were the ATLAS 1 and 
ATLAS 2 studies. The results of the two trials were combined in a prespecified pooled analysis. ${ }^{19}$ These two parallel, doubleblind, multinational, noninferior clinical trials randomized a total of 1867 patients to receive telavancin $10 \mathrm{mg} / \mathrm{kg}$ intravenously once a day or vancomycin $1 \mathrm{~g}$ every 12 hours (which could be dose-adjusted based upon the standards at each institution). Therapy was administered for 7-14 days depending on severity and location of infection. The primary endpoint was test of cure in all-treated and clinically evaluable populations. The clinically nonevaluable population was defined as those patients who were lost to follow-up, had withdrawn consent, died, had an indeterminate response to the antimicrobials, received prohibited antimicrobials, or received less than seven days of antimicrobials. A pathogen was cultured in $74 \%$ of all treated patients, of which $83 \%$ were identified as $S$. aureus. Of the $S$. aureus cultures, $52 \%$ were MRSA. In the population considered clinically evaluable, clinical cure occurred in $88.3 \%$ of those in the telavancin group and $87.1 \%$ of those in the vancomycin group (95\% confidence interval [CI]: -2.1-4.6). Among patients with MRSA cultures, cure was achieved in $90.6 \%$ of those in the telavancin group and $84.4 \%$ of those in the vancomycin group (95\% CI: $-1.1-9.3)$. In both trials, the mean length of therapy was about one day shorter with telavancin than with vancomycin. Adverse events occurred in $7 \%$ of those treated with telavancin and $4 \%$ of those treated with vancomycin. Therapy was discontinued due to serious adverse events (mostly commonly a cardiac, respiratory, or infectious event) in $8 \%$ of those in the telavancin group and in $6 \%$ of those in the vancomycin group. Additional detail regarding adverse drug reactions is provided in the safety section of this review.

In a retrospective subanalysis of the ATLAS trials, the efficacy of telavancin for surgical site infections was assessed in 194 patients (telavancin $n=101$, vancomycin $n=93$ ). A Gram-positive organism was identified in every patient included in the analysis. S. aureus was isolated in $49 \%$ of patients $(n=95)$ and MRSA was identified in $22 \%$ of all patients $(n=42)$. The median length of therapy was 10 days in both treatment groups. The clinical cure rate was similar between telavancin and vancomycin ( $77.2 \%$ versus $69.9 \%$, respectively) in the all-treated population, and not statistically significant (95\% CI: -5.1-24.2). Among patients infected with MRSA, the cure rate was $85.7 \%$ in the telavancin group and $71.4 \%$ in the vancomycin group. The differences in cure rates between treatment groups did not reach statistical significance $(95 \%$ CI: -11.3-37.4). Therapy was discontinued due to adverse events in $12 \%$ of patients in the telavancin group and $10 \%$ of patients in the vancomycin group. The adverse events that led to discontinuation occurred in $<2 \%$ of either treatment group. ${ }^{20}$

\section{Safety}

Adverse events attributed to treatment in the ATLAS 1 and 2 Phase III trials were assessed in 929 patients treated with telavancin and 938 patients treated with vancomycin. Nausea (15\% versus $27 \%$ ), taste disturbance described as "soapy" or metallic (33\% versus $7 \%$ ), insomnia (10\% versus $9 \%$ ), foamy urine $(13 \%$ versus $3 \%)$, and headache $(14 \%$ versus $13 \%$ ) were the most common mild adverse events, respectively. In the FAST 2 trial, hypokalemia occurred more often in the telavancin group than in the standard therapy group (7\% of patients versus $0 \%$ respectively, $P=0.01$ ), but this was not as apparent in the ATLAS 1 or 2 trials. An increase in serum creatinine was observed more frequently in the telavancin-treated group than in the control therapy group in all trials, although this difference did not reach statistical significance. This increase was usually mild and most cases were reversible after discontinuation of therapy. Higher renal adverse events were seen in patients greater than 65 years of age, comorbidities affecting kidney function, or concomitant medications that can affect kidney function. Electrocardiographic data from all trials demonstrated a prolongation in QTc (Fridericia corrected) interval associated with telavancin treatment. This prolongation was $6.4 \mathrm{msec}$ and $12.5 \mathrm{msec}$ in the FAST and FAST 2 trials, respectively, which is comparable with the QTc prolongation caused by quinolone antibiotics. ${ }^{17,18}$ Further information was gathered in a separate study of 160 patients randomized to receive intravenous telavancin $7.5 \mathrm{mg} / \mathrm{kg}, 15 \mathrm{mg} / \mathrm{kg}$, moxifloxacin $400 \mathrm{mg}$, or placebo. QTc intervals of $4.1 \mathrm{msec}(P=0.036)$, $4.5 \mathrm{msec}(P=0.027)$, and $9.2 \mathrm{msec}(P<0.001)$ were noted accordingly. However, no cardiac adverse events were reported to be caused by this QTc prolongation. ${ }^{21}$

Telavancin shares much of the same structure as vancomycin, and as a result has many of the same precautions. ${ }^{9}$ The cross-sensitivity of telavancin with vancomycin is unknown because patients with a documented allergy to vancomycin were excluded from clinical trials; consequently it should be avoided in patients with documented hypersensitivity or intolerance to vancomycin. Telavancin has been associated with infusion-related reactions like other glycopeptide antimicrobials, such as red man syndrome-like reactions, including flushing of the upper body, urticaria, pruritis, or rash. ${ }^{12}$ Therefore, it should be administered over 60 minutes or even slower or stopped to cease any of these reactions. 
Telavancin is listed as pregnancy category $\mathrm{C}$, meaning that animal data suggest telavancin may be teratogenic in humans. A black box warning states that women of child-bearing age should have a serum pregnancy test prior to the initiation of telavancin, and used only if the benefits outweigh the risks. A pregnancy registry has been developed to monitor outcomes in patients exposed to telavancin during pregnancy because there are no human pregnancy data. ${ }^{9}$ Astellas has also developed a risk evaluation and mitigation system for telavancin in order to inform all involved prescribing and dispensing health care professionals of its potential toxicity in pregnancy. Health care professional letters were distributed prior to commercial distribution, and then again at six months, 12 months, and 24 months after product approval. ${ }^{22}$

Telavancin does not interfere with the coagulation cascade, but it can affect some tests that monitor coagulation when drawn within 18 hours of telavancin administration. Prothrombin time, international normalized ratio, activated partial thromboplastin time, activated clotting time, and coagulationbased Factor Xa tests have all been shown to be falsely elevated following telavancin infusion. Telavancin can bind to the artificial phospholipid surfaces added to common anticoagulation tests, and interfere with the coagulation complexes to assemble on the surface of phospholipids and promote clotting in vitro. It is recommended by the manufacturer to draw these coagulation monitoring samples prior to the next telavancin dose administered so that there is minimal drug interference. There has been no evidence of increased bleeding risk, hypercoagulability, or effect on platelet aggregation. ${ }^{9}$

\section{Discussion}

In the contemporary drug arena, any new pharmaceutical coming to market must offer a clear advantage over the current standard of therapy to be incorporated into practice. Efficacy, safety, and cost are most often considered. Telavancin has demonstrated efficacy for the treatment of SSSI caused by Grampositive bacteria, although it was not better than the standard of therapy. In clinical trials, patients treated with telavancin achieved a clinical cure one day earlier than standard therapy. This may allow for shorter hospital stays with telavancin. With the development of resistance to standard therapy, telavancin's bactericidal activity may give it a therapeutic edge in the future for bacteria that are resistant to vancomycin. Telavancin currently only provides a modest improvement in efficacy compared with established Gram-positive antibiotics.

Given that telavancin has the same efficacy as standard therapy, determining its place in therapy should be based on side effect profile, administration issues, and cost. The once-daily dosing of telavancin provides an advantage over other established therapy which can be dosed two to four times a day. Unlike other glycopeptides, serum level monitoring is not required for treatment with telavancin. Having the same basic structure as vancomycin gives telavancin a similar side effect profile to that of vancomycin. Telavancin was associated with more nephrotoxicity, hypokalemia, and taste disturbances than vancomycin in clinical trials making it a less promising option. It is not recommended to use telavancin in pregnant women, and caution is advised when using other medications that cause corrected QT interval prolongation. At current average wholesale pricing, telavancin is one of the most expensive options third only to daptomycin and intravenous linezolid (Table 2). Venous access must be maintained during treatment with telavancin because there is no enteral formulation of telavancin available.

\section{Summary}

Telavancin is an intravenously administered lipoglycopeptide that exhibits potent in vitro activity against most clinically significant Gram-positive bacteria, including MRSA and glycopeptide-intermediate staphylococcal species. A long half-life and post-antibiotic effect affords once-daily dosing of telavancin. Serum drug level monitoring is not required, although patients with reduced renal function do require dose adjustments. Telavancin was approved for the treatment of SSSI based on the results of two Phase II and two Phase III trials in which telavancin was found to be noninferior as compared with standard therapy. Telavancin displays a similar side effect profile compared with that of vancomycin, with the exception of higher rates of hypokalemia, creatinine elevation, and QTc prolongation. Although the approval of

Table 2 Cost of common drugs for Gram-positive skin and soft tissue infections

\begin{tabular}{|c|c|c|}
\hline Enteral & Dose* & Cost/day ${ }^{\dagger}$ \\
\hline Cephalexin & $500 \mathrm{mg} 4$ times a day & $\$ 5.32$ \\
\hline Clindamycin & $300-600 \mathrm{mg} q 4-6 \mathrm{hrs}$ & $\$ 9.28$ \\
\hline Dicloxacillin & $500 \mathrm{mg} 4$ times a day & $\$ 4.80$ \\
\hline Linezolid & $600 \mathrm{mg} \mathrm{q} / 2 \mathrm{hrs}$ & $\$ 183.95$ \\
\hline $\begin{array}{l}\text { Trimethoprim- } \\
\text { sulfamethoxazole }\end{array}$ & $\begin{array}{l}\text { I-2 double strength } \\
\text { tablets q8-12 hrs }\end{array}$ & $\$ 1.76$ \\
\hline Intravenous & Dose* & Cost/day ${ }^{\dagger}$ \\
\hline Clindamycin & 600 mg q8 hrs & $\$ 12.00$ \\
\hline Daptomycin & 4-6 mg/kg/day & $\$ 272.70$ \\
\hline Linezolid & $600 \mathrm{mg} \mathrm{q} / 2 \mathrm{hrs}$ & $\$ 240.20$ \\
\hline Telavancin & $10 \mathrm{mg} / \mathrm{kg} /$ day & $\$ 186.00$ \\
\hline Tigecycline & $100 \mathrm{mg} \times \mathrm{I}$, then $50 \mathrm{mg}$ q $12 \mathrm{hrs}$ & $\$ 147.00$ \\
\hline Vancomycin & $15-20 \mathrm{mg} / \mathrm{kg}$ q8-12 hrs & $\$ 13.48$ \\
\hline
\end{tabular}

Notes: *Reflects a standard regimen for the treatment of SSSI in adults. with normal renal and hepatic function. ${ }^{\dagger}$ Cost data is acquisition wholesale price. 
telavancin allows for its use as an alternative for the treatment of SSSI caused by MRSA, glycopeptide-intermediate staphylococci, and multidrug-resistant streptococci, its role for the treatment of vancomycin-resistant enterococci is limited due to elevated in vitro minimum inhibitory concentrations and lack of outcome data. Telavancin is likely a costly alternative to standard therapy. Consequently, its place in therapy has yet to be determined.

\section{Disclosure}

The authors report no conflicts of interest in this work.

\section{References}

1. Edelsberg J, Taneja C, Zervos M, et al. Trends in US hospital admissions for skin and soft tissue infections. Emerg Infect Dis. 2009;15: 1516-1518.

2. Guidance for Industry. Uncomplicated and complicated skin and skin structure infections: Developing antimicrobial drugs for treatment. US Dept of Health and Human Services, Food and Drug Administration, Center for Drug Evaluation and Research, 1998. Available at: http:// www.fda.gov/CDER/guidance/2566dft.pdf. Accessed 2010 Apr 1.

3. Stevens DL, Bisno AL, Chamber HF, et al. Practice guidelines for the diagnosis and management of skin and soft-tissue infections. Clin Infect Dis. 2005;41:1373-1406.

4. Moet GJ, Jones RN, Biedenbach DJ, Stilwel MG, Fritsche TR. Contemporary causes of skin and soft tissue infection in North America Latin America, and Europe: report from SENTRY Antimicrobial Surveillance Program (1998-2004). Diagn Microbiol Infect Dis. 2007; 57:7-13.

5. Herold BC, Immergluck LC, Maranan MC, et al. Community-acquired methicillin-resistant Staphylococcus aureus in children with no identified predisposing risk. JAMA. 1998;279:593-598.

6. DuFour P, Gillet Y, Bes M, et al. Community-acquired methicillinresistant Staphylococcus aureus infections in France: Emergence of a single clone that produces Panton-Valentine leukocidin. Clin Infect Dis. 2002;35:819-824.

7. Naimi TS, LeDell KH, Como-Sabetti K, et al. Comparison of communityand health care-associated methicillin-resistant Staphylococcus aureus infection. JAMA. 2003;290:2976-2984.

8. Boucher HW, Corey GR. Epidemiology of methicillin-resistant Staphylococcus aureus. Clin Infect Dis. 2008;46:S344-S349.

9. Vibativ $^{\circledR}$ (telavancin) Package insert. Deerfield, IL: Astellas Pharma, Inc.; 2009.

10. Higgins DL, Chang R, Debabov DV, et al. Telavancin a multifunctional lipoglycopeptide, disrupts both cell wall synthesis and cell membrane integrity in methicillin-resistant Staphylococcus aureus. Antimicrob Agents Chemother. 2005;49:1127-1134.

11. Laohavaleeson S, Kuti JL, Nicolau DP. Telavancin: A novel lipglycopeptide for serious Gram-positive infections. Expert Opin Investig Drugs. 2007;16:347-357.
12. Shaw JP, Seroogy J, Kaniga K, Higgins DL, Kitt M, Barriere SL. Pharmacokinetics, serum inhibitory and bactericidal activity, and safety of telavancin in healthy subjects. Antimicrob Agents Chemother. 2005; 49:195-201.

13. Wong SL, Barriere SL, Kitt MM, Goldberg MR. Multiple-dose pharmacokinetics of intravenous telavancin in healthy male and female subjects. J Antimicrob Chemother. 2008;62:780-783.

14. Wong SL, Goldberg MR, Ballow CH, Kitt MM, Barriere SL. Effect of telavancin on the pharmacokinetics of the cytochrome $\mathrm{P} 4503 \mathrm{~A}$ probe substrate midazolam: A randomized, double-blind, crossover study in healthy subjects. Pharmacotherapy. 2010;2:136-143.

15. Patel JH, Churchwell MD, Seroogy JD, Barriere SL, Grio M, Mueller BA. Telavancin and hydroxyl propyl- $\beta$-cyclodextrin clearance during continuous renal replacement therapy: An in vitro study. Int $J$ Artif Organs. 2009;32:745-751.

16. Draghi DC, Benton BM, Krause KM, Thornsberry C, Pillar C, Sahm DF. Comparative surveillance study of telavancin activity against recently collected Gram-positive clinical isolates from across the United States. Antimicrob Agents Chemother. 2008;52:2383-2388.

17. Stryjewski ME, O'Riordan WD, Lau WK, et al. Telavancin versus standard therapy for treatment of complicated skin and soft-tissue infections due to Gram-positive bacteria. Clin Infect Dis. 2005;40: 1601-1607.

18. Stryjewski ME, Chu VH, O'Riordan WD, et al. Telavancin versus standard therapy for treatment of complicated skin and skin structure infection caused by Gram-positive bacteria: FAST 2 study. Antimicrob Agents Chemother. 2006;50:862-867.

19. Stryjewski ME, Graham DR, Wilson SE, et al. Telavancin versus vancomycin for the treatment of complicated skin and skin-structure infections caused by Gram-positive organisms. Clin Infect Dis. 2008; 46:1683-1693.

20. Wilson SE, O'Riordan W, Hopkins A, Friedland HD, Barriere SL, Kitt MM. Telavancin versus vancomycin for the treatment of complicated skin and skin-structure infections associated with surgical procedures. Am J Surg. 2009;197:791-796.

21. Barriere S, Genter F, Spencer E, Kitt M, Hoelscher D, Morganroth J. Effects of a new antibacterial, telavancin, on cardiac repolarization (QTc interval duration) in healthy subjects. J Clin Pharmacol. 2004; 44:689-695

22. US Food and Drug Administration. Available at: http://www. fda.gov/Drugs/DrugSafety/PostmarketDrugSafety InformationforPatientsandProviders/ucm111350.htm. Accessed 2010 Jul 15. Cubicin $^{\circledR}$ (daptomycin) Package insert. Lexington, MA: Cubist Pharmaceuticals; 2010.

Synercid $^{\circledR}$ (quinupristin/dalfopristin) Package insert. Bristol, TN: King Pharmaceuticals; 2003.

Zyvox $^{\circledR}$ (linezolid) Package insert. New York, NY: Pfizer, Inc, 2009.

Tygacil $^{\circledR}$ (tigecycline) Package insert. Philadelphia, PA: Wyeth Pharmaceuticals; 2009

Zhanel GG, Trapp S, Gin AS, et al. Dalbavancin and telavancin: Novel lipoglycopeptides for the treatment of gram-positive infections. Expert Rev Anti Infect Ther. 2008;6:67-81.
Clinical, Cosmetic and Investigational Dermatology

\section{Publish your work in this journal}

Clinical, Cosmetic and Investigational Dermatology is an international, peer-reviewed, open access, online journal that focuses on the latest clinical and experimental research in all aspects of skin disease and cosmetic interventions. All areas of dermatology wil be covered; contributions will be welcomed from all clinicians and

\section{Dovepress}

basic science researchers globally. This journal is indexed on CAS. The manuscript management system is completely online and includes a very quick and fair peer-review system, which is all easy to use. Visit http://www.dovepress.com/testimonials.php to read real quotes from published authors. 